Research Article

\title{
Physicomechanical Assessments and Heavy Metals' Leaching Potential of Modified Asphalt Binders Incorporating Crumb Rubber and Tin Slag Powders
}

\author{
Ali Huddin Ibrahim, ${ }^{1}$ Mohd Rosli Mohd Hasan (D), ${ }^{1}$ Ashiru Sani, ${ }^{2}$ Sharvin Poovaneshvaran, ${ }^{1}$ \\ Tracy Leh Xin Wong, ${ }^{1}$ Megat Azmi Megat Johari, ${ }^{1}$ Kok Keong Choong, \\ and Ramadhansyah Putra Jaya ${ }^{3}{ }^{3}$

\begin{abstract}
${ }^{1}$ School of Civil Engineering, Universiti Sains Malaysia (Engineering Campus), Nibong Tebal 14300, Pulau Pinang, Malaysia
${ }^{2}$ Department of Civil Engineering, Kano University of Science and Technology, Wudil 3244, Kano, Nigeria

${ }^{3}$ Department of Civil Engineering, College of Engineering, Universiti Malaysia Pahang, Gambang 26300, Kuantan, Pahang, Malaysia
\end{abstract}

Correspondence should be addressed to Mohd Rosli Mohd Hasan; cerosli@usm.my

Received 17 July 2021; Accepted 16 September 2021; Published 27 September 2021

Academic Editor: Antonio Gloria

Copyright (c) 2021 Ali Huddin Ibrahim et al. This is an open access article distributed under the Creative Commons Attribution License, which permits unrestricted use, distribution, and reproduction in any medium, provided the original work is properly cited.

\begin{abstract}
Industrial solid waste has been widely used as an alternative additive for bituminous material modification. This study aims to evaluate the basic properties and quantify the leaching potential of modified asphalt binders incorporating crumb rubber powder (CRP) from waste tires and tin slag (TS) for a local smelting company. Three percentages of CRP and TS, at 5, 10, and 15\%, were considered. The conventional asphalt binder (PEN 60/70), CRP, and TS-based modified asphalt binders were analyzed for toxicity, softening point, penetration value, elastic recovery, torsional recovery (TR), and coatability index. The findings indicated that the addition of the waste materials led to no significant heavy metal content in the asphalt binder mix. Moreover, the basic and physical properties of the asphalt binders were also improved by 5,10 , and $15 \%$ of the waste, respectively. However, TS waste exhibited limited effects on all the parameters and had a 5\% optimum dosage. The modified binders' results showed that the CRP modified asphalt binders had fewer heavy metals and responded more to elastic recovery and coatability.
\end{abstract}

\section{Introduction}

In Malaysia, the escalated usage of vehicles on roads generates a huge amount of waste tires at the end of their life cycle [1]. Up to mid-2017, there were 28,181,203 units of vehicles registered, as reported by the Malaysia Automotive Association (MAA) [2]. As a developing country, the huge increase in the generation of scrap tires is alarming. The disposal of waste tires poses a major environmental problem, as they have a long lifespan and possess nonbiodegradable properties. Disposal of waste tires is a challenging task as it will lead to scarcity of landfills capacity due to its large quantity $[2,3]$. This issue can be overcome by recycling scrap tires to protect the environment from pollution $[4,5]$. Since the last few decades, recycled waste tires are being utilized as a modifier in asphalt paving mixtures, additives in Portland cement concrete, and lightweight fillers. In addition, the tires can also serve as the crash barrier, a bumper, and an artificial reef $[3,6,7]$. The utilization of waste tires is effective in overcoming the issue associated with solid scrap tire disposal, and the recycled tires such as crumb rubber can act as a good modifier for enhancing the properties and performance of asphaltic concrete $[2,8,9]$. The utilization of polymer-modified bitumen is a cost-effective and efficient alternative to improve the performance of asphalt pavements $[10,11]$.

Vehicle tire shreds are usually found in the range of $460 \mathrm{~mm}$ to $25 \mathrm{~mm}$, and thus, the small sizes of shred and chip 
eased the production of ground crumb rubber [12]. The wire and other metal contaminants are removed [12-14]. The applications of crumb rubber in asphalt paving mixtures are known as rubber asphalt in the USA. It consists of asphalt cement, reclaimed tire rubber, and additives. According to the reports, approximately $15 \%$ of the rubber components are integrated into the rubber asphalt blend. During the blending process, grounded rubber particles were mixed with hot asphalt cement, resulting in swelling of the rubber particles [15]. The particles size of CRP influenced the physical properties of modified binders. Studies reported that the particle size of crumb rubber, which is subjected to high temperature, was an influential factor in viscoelastic properties $[16,17]$.

On the other hand, tin slag is formed through the smelting process of tin. Recently, a company from Penang managed to produce 27,172 tonnes of tin metal, thus making Penang the largest tin producer in Malaysia. Malaysia is known as the third-largest tin metal supplier globally, leading in the production of tin metal and tin-based products, as well as custom tin smelting [18]. Cassiterite is reduced to form tin metal with carbon at a very high temperature $\left(1200^{\circ} \mathrm{C}\right.$ to $\left.1300^{\circ} \mathrm{C}\right)$. Currently, the lack of commercial application of tin slag and its unsuitability for disposal in landfills has resulted in the accumulation of a large quantity of waste that poses a disposal concern for smelting plant companies. The TS generally consists of $\mathrm{SiO}_{2}$, $\mathrm{Al}_{2} \mathrm{O}_{3}, \mathrm{CaO}, \mathrm{Fe}_{2} \mathrm{O}_{3}$, and $\mathrm{TiO}_{2}$. The elements such as $\mathrm{Pb}, \mathrm{Cr}$, and $\mathrm{Mn}$ in TS tend to be soluble in an acid environment [19]. With stringent environmental restrictions by the government and local authorities, treatment, and disposal issues for scheduled waste are getting more attention from manufacturers or industry authorities. Along with this, an alternative approach such as reusing or recycling industrial waste or by-products has been considered. The outcome of previous research shows that those products are feasible to be used in road pavement construction as binder modifiers with and without additives [20-24].

However, incorporating various industrial wastes into asphalt binders has compelled me to conduct related studies to ascertain that the heavy metals are present in the CRP and TS modified binders. The studies are to ensure its environmental sustainability through the use of asphalt pavement technology. This study is also partially intended to examine the basic and physical characteristics of CRP and TS modified binders. Therefore, this study mainly aims to evaluate the possibility of adding different industrial wastes (CRP and TS) as additives to bituminous materials.

\section{Materials and Methods}

2.1. Materials. The physical properties of conventional asphalt binder (PEN 60/70) used for the sample preparation in this study are shown in Table 1 . The dosages of industrial waste that are used to modify asphalt binders, namely, crumb rubber powder (CRP) and tin slag (TS), are provided in Table 2. The CRP and TS industrial waste adopted were supplied by Malaysia's Pan Century Oleochemicals Sdn Bhd. and Penang's Malaysia Smelting Corporation Berhad
TABLe 1: The bitumen properties.

\begin{tabular}{lc}
\hline Physical properties & Results \\
\hline Torsional recovery & $0.5 \%$ \\
Softening point & $50^{\circ} \mathrm{C}$ \\
Elastic recovery & $83 \%$ \\
Penetration & $65 \mathrm{dmm}$ \\
Flash point & $273^{\circ} \mathrm{C}$ \\
\hline
\end{tabular}

TABle 2: Percentages of additives used.

\begin{tabular}{lccc}
\hline Types of additives & Designation & Dosages (\%) & $\begin{array}{c}\text { Sample } \\
\text { designation }\end{array}$ \\
\hline \multirow{3}{*}{ Crumb rubber powder } & CRP & 5 & $5 \%$ CRP \\
& & 10 & $10 \%$ CRP \\
Tin slag & & 5 & $15 \%$ CRP \\
\hline & TS & 10 & $5 \%$ TS \\
& & 15 & $15 \%$ TS \\
\hline
\end{tabular}

(MSC). The physical appearance of the CRP is shown in Figure 1(a). The CRP is a processed waste tire, in which the size of the tire is reduced by grounding it into smaller particles. The distribution of particle size for both the CRP and TS is shown in Figure 2. TS was initially dried in an oven at $105 \pm 5^{\circ} \mathrm{C}$ for 24 hours and then grounded for 8 hours to obtain finer particles using a laboratory scale ball mill. The tin slag went through a $75 \mu \mathrm{m}$ sieve to remove coarser particles, as shown in Figure 1(b). The tin slag chemical composition is shown in Table 3 [25]. All samples were prepared using a liquid antistripping agent at $0.1 \%$ Silane additive based on the binder weight.

\subsection{Preparation of Samples}

2.2.1. Preparation of the Sample for Toxicity Characteristic Leaching Procedure (TCLP) Test. Initially, the asphalt binder in galvanized iron containers was preheated at $160^{\circ} \mathrm{C}$ for 1 hour. Besides that, modified binders with different dosages (5\%, $10 \%$, and $15 \%)$ of CRP and TS were also prepared to compare the impact of various dosages on the quantity of detected heavy metals. Before testing, the preheated modified binder in each galvanized iron container was manually stirred for 1 minute to improve its consistency. Then, the sample was poured into a container and cooled to room temperature for 1 hour prior to the test. The toxicity of the conventional and modified asphalt binders was tested according to US EPA Method 1311, Toxicity Characteristic Leaching Procedure (TCLP) [26] by using the water from the purification system (Figure 3(a)) and an automatic rotary agitator as shown in Figure 3(b).

\subsubsection{Preparation of the Sample for the Physical Property} Tests. The TS and CRP modified binders were prepared using three dosages at $5 \%, 10 \%$, and $15 \%$ by weight of asphalt binder. The incorporation of waste materials (TS that was passing $75 \mu \mathrm{m}$ or CRP passing $1 \mathrm{~mm}$ ) was incorporated in 


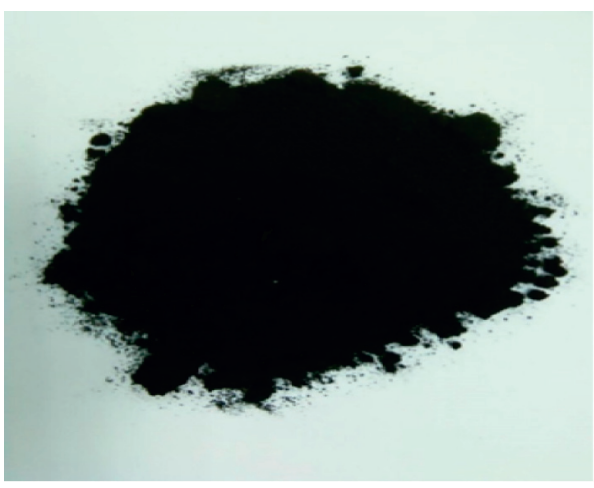

(a)

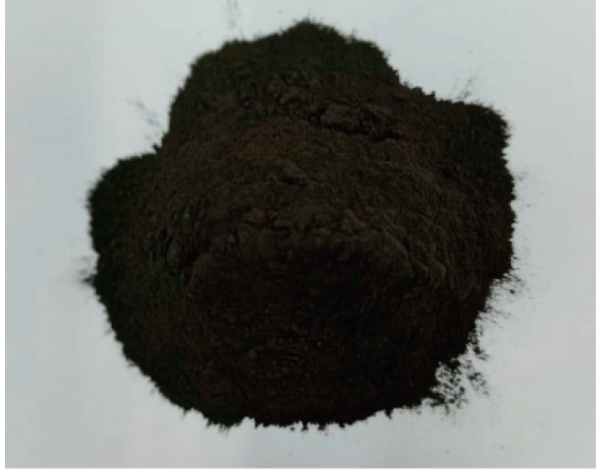

(b)

FIgure 1: Physical appearance of industrial waste powders. (a) Crumb rubber powder. (b) Tin slag.

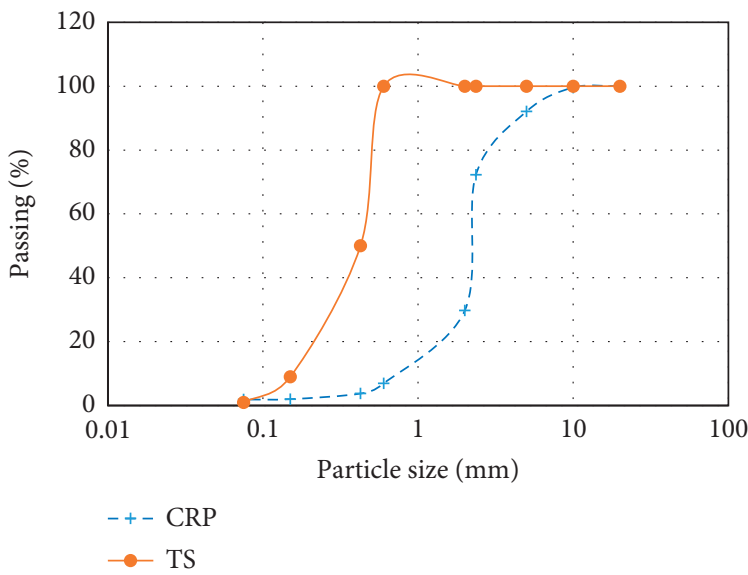

FIgURe 2: Particle size distribution of crumb rubber powder (CRP) and tin slag (TS).

TABLE 3: Chemical composition of tin slag.

\begin{tabular}{lccccccccccc}
\hline $\mathrm{CaO}(\%)$ & $\mathrm{SiO}_{2}(\%)$ & $\mathrm{Al}_{2} \mathrm{O}_{3}(\%)$ & $\mathrm{MgO}(\%)$ & $\mathrm{FeO} / \mathrm{Fe}_{2} \mathrm{O}_{3}(\%)$ & $\mathrm{WO}(\%)$ & $\mathrm{As}(\%)$ & $\mathrm{Pb}(\%)$ & $\mathrm{Cd}(\%)$ & $\mathrm{TiO}_{2}(\%)$ & $\mathrm{Sn}(\%)$ & $\mathrm{Zn}(\%)$ \\
\hline $16-20$ & $28-32$ & $10-13$ & $2-4$ & $13-18$ & 20 & $<0.01$ & $<0.01$ & $<0.0001$ & $4-6$ & $<0.3$ & $<0.14$ \\
\hline
\end{tabular}

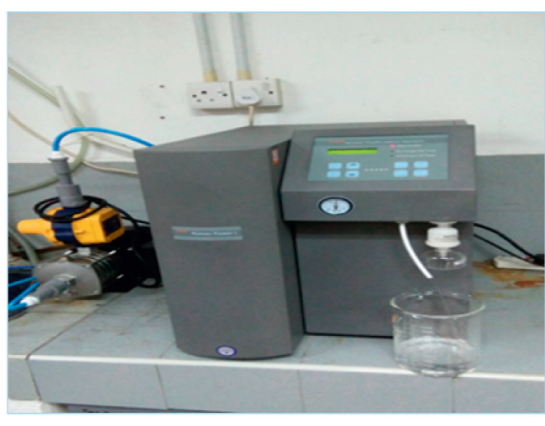

(a)

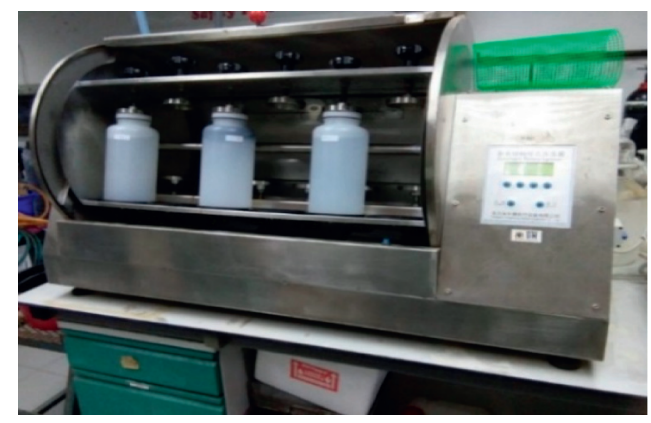

(b)

FIgURE 3: TCLP test assembly. (a) Water purification machine. (b) Automatic rotary agitator.

the binder via a wet process. Firstly, the conventional asphalt binder was preheated at a temperature of $160^{\circ} \mathrm{C}$ before blending. After that, the waste materials were incorporated into the binder for 30 minutes at a temperature of $160^{\circ} \mathrm{C}$ in a high-shear mixer. The waste materials were added gently into the binder to avoid clumping to produce a homogenous 
modified binder. The mixing speed of the high-shear mixer to blend the waste material and binder was set at $1000 \mathrm{rpm}$.

\section{Test Methods}

3.1. Toxicity Characteristic Leaching Procedure (TCLP). The testing was initiated by preparing samples of bitumen, CRP, or TS mixed binder of about $100 \mathrm{~g}$ with each placing in a $2 \mathrm{~L}$ plastic bottle together with extractor fluid \#1 used as leaching fluid. The buffer chosen for the extraction of fluid depends on the $\mathrm{pH}$ of the samples. The preparation of extraction fluid \#1 was started by mixing glacial acetic acid $\left(\mathrm{CH}_{3} \mathrm{COOH}\right)(5.7 \mathrm{~mL})$ into $1 \mathrm{~L}$ Type II reagent water, followed with the addition of $1 \mathrm{~N} \mathrm{NaOH}(64.3 \mathrm{~mL})$, and diluted it to the volume of $2 \mathrm{~L}$ with final $\mathrm{pH} 4.93 \pm 0.05$. Type II reagent water was filtered by the New Human Power System water filter (Figure 3(a)). Referring to Figure 3(b), the plastic bottles were placed in an Automatic Rotary Agitator at $18 \pm 2 \mathrm{~h}$ at room temperature. After agitation, the samples were filtrated with $0.7 \mu \mathrm{m}$ glass microfiber filters. The filtered samples were collected and analyzed for 21 chemical elements. The concentrations (ppm) of chemical elements such as arsenic (As), beryllium (Be), calcium (Ca), cadmium (Cd), cobalt $(\mathrm{Co})$, chromium $(\mathrm{Cr})$, copper $(\mathrm{Cu})$, iron $(\mathrm{Fe})$, lithium (Li), magnesium $(\mathrm{Mg})$, manganese $(\mathrm{Mn})$, molybdenum (Mo), nickel $(\mathrm{Ni})$, lead $(\mathrm{Pb})$, antimony $(\mathrm{Sb})$, selenium $(\mathrm{Se})$, strontium (Sr), thallium (Ti), thallium (Tl), vanadium (V), and zinc $(\mathrm{Zn})$ were determined by state-of-the-art equipment namely ICP-OES (Varian 715-ES ICP Optical Emission Spectrometer). The same approach was repeated for tin slag samples. Table 4 shows the United States Environmental Protection Agency (US EPA).

3.2. Basic Properties of Asphalt Binders. The asphalt binder basic tests were carried out using the penetration, softening point, elastic recovery, and torsional recovery tests. The penetration test was performed in accordance with ASTM D5 [28] to evaluate the differences in penetration grade and the consistency of asphalt binders. Likewise, the softening point test determined the temperature of the initial asphalt binder response as followed by the ASTM D36 procedure [29]. Moreover, the determination of temperature susceptibility of crumb rubber and tin slag modified asphalt binders was evaluated from the penetration index (PI), which was obtained from the penetration and softening point test. The calculation of penetration index is shown in Shell Bitumen Handbook as stated in the following equation:

$$
\mathrm{PI}=\frac{1952-500 \log (\operatorname{Pen} 25)-20 \times \mathrm{SP}}{50 \log (\operatorname{Pen} 25)-\mathrm{SP}-120},
$$

where $\operatorname{Pen}_{25}$ refers to the penetration at $25^{\circ} \mathrm{C}$, and SP refers to the softening point temperature of modified asphalt binder.

The elastomeric characteristics of the asphalt binder and modified binders were ascertained via elastic recovery and torsional recovery. The elastic recovery test was done by following AASHTO T51 and ASTM D6084 [30, 31]. This elastic testing was conducted at $25^{\circ} \mathrm{C}$ according to ASTM
TABLE 4: Metals' hazardous waste parameters by the US EPA [27].

\begin{tabular}{lc}
\hline Metals & Regulatory level (ppm) \\
\hline Arsenic (As) & 5.0 \\
Barium (Ba) & 100.0 \\
Cadmium (Cd) & 1.0 \\
Chromium (Cr) & 5.0 \\
Lead (Pb) & 5.0 \\
Mercury (Hg) & 0.2 \\
Selenium (Se) & 1.0 \\
Silver $(\mathrm{Ag})$ & 5.0 \\
\hline
\end{tabular}

specification, in which the binder specimens were pulled apart in a ductilometer and held after reaching a specified elongation during the test. The specimens are then cut in the middle of the elongation, and the percent recovery of each specimen is determined [31].

The torsional recovery test is an inventive method in determining the elasticity in the asphalt binder. It was conducted following the ARRB AG: PT/T112 procedure [32] at $25^{\circ} \mathrm{C}$. This test was performed by embedding a metal disc in a cup of asphalt, and the sample container was rotated at $180^{\circ}$. Then, the band was removed, and the specimen was left aside to recover for 30 seconds. The torsional recovery percentage $\left(T_{R}\right)$ was calculated by the following equation:

$$
T_{R}=\frac{A}{180} \times 100,
$$

where $A$ is recovered angle, in degrees.

3.3. Binder Coatability Test. The coatability of the asphalt mixtures was determined based on the aggregate absorption method in accordance with the AASHTO T 195 [33]. In this method, only coarse aggregate particles are considered. The short-term aged coated aggregate with a soaking time of 60 minutes was presumed that a completely coated aggregate would demonstrate high resistance towards the diffusion of water due to the presence of asphalt film that covered the aggregate surface. Otherwise, a coated aggregate could be prone to water absorption by allowing the water to diffuse into the partly coated aggregate [34-36].

This study determined the coatability of asphalt base binder and modified asphalt mixtures by the following procedures. Firstly, the $20 \mathrm{~mm}$ coarse aggregate was wetsieved in order to remove the excessive fine particles. Then, the coarse aggregate was dried in an oven at a temperature of $105 \pm 5^{\circ} \mathrm{C}$ for $24 \pm 0.5$ hours. Oven-dried coarse aggregate was sieved, and the portion retained on the $10 \mathrm{~mm}$ sieve size was used to prepare the sample. A 2,000 g batch sample consisted of $26 \%$ of aggregate between $20 \mathrm{~mm}$ and $14 \mathrm{~mm}$, and $74 \%$ of aggregate with sizes ranging from $14 \mathrm{~mm}$ to $10 \mathrm{~mm}$ was prepared. Six individual batches were formed from coarse aggregate gradations following Marshall mix design, with three batches sample of $2,000 \mathrm{~g}$ subjected to preheating at a mixing temperature of $160^{\circ} \mathrm{C}$ for four hours, and the others were stored at the room temperature. The considerations have taken to their rheological behavior at mixing, and construction temperature, the base asphalt 
binder, and modified asphalt binder were subjected to a high temperature of $163^{\circ} \mathrm{C}$ for at least 85 minutes to simulate the short-term aging process artificially. The aging process was conducted in accordance with ASTM D 2872 [37].

Mix design and the surface area distribution of the coarse aggregate fraction determined the required amount of binder. Equations (3) to (6) were used to compute the binder content and the output parameters such as absorption of loss mixture aggregate, absorption of aggregate, and coating index of each mixture. The input parameters used for the sample preparation are presented in Table 5. The amount of binder of $41.25 \mathrm{~g}$ was mixed with the $2,000 \mathrm{~g}$ of coarse aggregate fraction batch. The optimum binder content (OBC) of $\mathrm{Pb}$ was obtained from the Marshall mix design. The asphalt binders were subjected to heating for two hours. Then, the loose mixture was placed into a bucket mixer for 60 seconds before being transferred into a tray and heated in the oven for the next two hours. These allow for binder absorption and induce the short-term aging process during production simultaneously. Moreover, the loose mixture was cooled at room temperature overnight. Both aggregates and loose mixture were exposed to water for 60 minutes. Then, a dry towel was used to remove the excess water until the saturated surface dried (SSD) condition was achieved. The masses obtained for aggregate and loose mixture in SSD condition were recorded as $W_{\text {agg-SSD }}$ and $W_{\text {loose-SSD, }}$ respectively.

$$
\begin{aligned}
\text { Binder content, } W_{b} & =W_{\mathrm{agg}} \times \frac{P_{b}}{100-P_{b}} \times \frac{\mathrm{SA}_{\text {coarse }}}{\mathrm{SST}} \times \frac{1}{P_{s-\text { coarse }}}, \\
\mathrm{Abs} \%_{\text {loose }} & =\frac{W_{\text {loose-SSD }}-\left(W_{\mathrm{agg}}+W_{b}\right)}{W_{\mathrm{agg}}+W_{b}} \times 100, \\
\mathrm{Abs} \%_{\mathrm{agg}} & =\frac{W_{\mathrm{agg}-\mathrm{SSD}}-W_{\mathrm{agg}}}{W_{\mathrm{agg}}} \times 100, \\
\text { coating index } & =\frac{\mathrm{Abs} \%_{\mathrm{agg}}-\mathrm{Abs} \%_{\text {loose }}}{\mathrm{Abs} \%_{\mathrm{agg}}} \times 100 .
\end{aligned}
$$

The surface area of mix design combined with aggregates is calculated by adopting methods from previous studies and past laboratory work experiences regarding aggregate gradation [38]. The calculation for surface area determination is shown in Table 6.

\section{Results and Discussion}

4.1. Effect of Crumb Rubber and Tin Slag on the Leaching Potential. The current study investigates the potential leaching of heavy metals from crumb rubber, tin slag, and conventional asphalt binder through TCLP experiments. The collected leachates of the samples were analyzed for the heavy metals by Inductively Coupled Plasma Optical Emission Spectrometry (ICP-OES). The initial TCLP test was performed on raw material, namely, crumb rubber powder, tin slag, and unmodified asphalt binder. Next, the
TCLP test was performed on crumb rubber powder and tin slag incorporated asphalt mixture. The TCLP test was conducted at two different stages to deliver a thorough correlation between the leaching of raw materials and the incorporation of raw material into asphalt mixtures. Along with this, the research findings indicated the effect of asphalt binder in reducing the leaching of heavy metals from the raw materials. Furthermore, the findings of TCLP analysis for crumb rubber powder, tin slag, and asphalt binder can be used to portray the mobility of heavy metals and replicate the leaching situation, as heavy metals elements were leached by acid rain.

The unmodified asphalt binder was tested as a control sample. The filtered samples or leachate solution was analyzed for the chemical elements using optical emission spectroscopy (ICP VARIAN 715-OES). The results from the leachate solution of the unmodified asphalt binder analysis implied that the chemical elements such as Arsenic (As), Beryllium (Be), Cadmium (Cd), Cobalt (Co), Copper (Cu), Lithium ( $\mathrm{Li})$, Lead $(\mathrm{Pb})$, Strontium $(\mathrm{Sr})$, and Thallium $(\mathrm{Tl})$ were not detected. However, $\mathrm{Ca}, \mathrm{Cr}, \mathrm{Fe}, \mathrm{Mg}, \mathrm{Mn}, \mathrm{Mo}, \mathrm{Ni}, \mathrm{Sb}$, $\mathrm{Se}, \mathrm{Ti}, \mathrm{V}$, and $\mathrm{Zn}$ were detected via the conducted tests. The experimental results of the TCLP for these materials in Table 7 were expressed in part per million (ppm). Zinc was detected with the highest concentration recorded as $62 \mathrm{ppm}$ in crumb rubber powder, but it is still considered within the safe level compared to its maximum allowable limit of $250 \mathrm{ppm}$ in Table 4. Chromium and selenium, which are more hazardous, were obtained at a concentration of $0.007 \mathrm{ppm}$ and $0.235 \mathrm{ppm}$, respectively, for crumb rubber powder, while they were $0.003 \mathrm{ppm}$ and $0.078 \mathrm{ppm}$ for tin slag. Chromium was not detected in asphalt binder samples, yet selenium was detected at $0.134 \mathrm{ppm}$. Nevertheless, it is very much lower than the regulatory level according to the metals hazardous waste parameters by US EPA regulatory in Table 4 [27].

Meanwhile, the results in Table 8 show the detected metal elements concentrations for the samples of asphalt binder with the incorporation of crumb rubber powder at different concentrations. Generally, the trend of the experimental results showed that the increasing amount of crumb rubber powder caused a hike in certain heavy metal elements. A higher amount of heavy metals contamination for $\mathrm{Ca}, \mathrm{Fe}, \mathrm{Mg}$, and $\mathrm{Ti}$ was detected in the filtered leachate solution for a higher portion of crumb rubber powder. This proved that incorporating asphalt binder mixed with crumb rubber powder does not facilitate or has no effect in reducing these heavy metal elements in the leaching process, which primarily comes from crumb rubber powder. In the case of selenium, it was found to be eliminated in bitumen mixed for $5 \%, 10 \%$, and $15 \%$ added crumb rubber, but vanadium was slightly increased at $15 \%$ added crumb rubber in comparison to $5 \%$ and $10 \%$. There was a fluctuation for Mo, $\mathrm{Sb}$, and $\mathrm{Zn}$, which could be occurred due to many factors such as the varying portion of chemical elements in the crumb rubber added into the specimens.

The metals considered as hazardous such as As, $\mathrm{Cd}, \mathrm{Cr}$, and $\mathrm{Pb}$ were evaluated to be below detectable limits, except Se that was obtained at $0.171 \mathrm{ppm}$ but below $1 \mathrm{ppm}$ limit. 
TABLE 5: The amount of materials required for the sample preparation.

\begin{tabular}{lc}
\hline Parameters & Values \\
\hline The optimum of binder content, $\mathrm{Pb}$ & $5.0 \%$ \\
Coarse aggregate, $W_{\text {agg }}$ & $2,000 \mathrm{~g}$ \\
The surface area of the combined aggregate, $\mathrm{SA}_{\text {coarse }}$ & $0.41 \mathrm{~m}^{2} / \mathrm{kg}$ \\
The total surface area of mix design combined aggregate, SST & $5.507 \mathrm{~m}^{2} / \mathrm{kg}$ \\
Percentages of coarse aggregate retained on a $10 \mathrm{~mm}$ sieve, $P_{\text {s-coarse }}$ & $19 \%$ \\
\hline
\end{tabular}

TABLE 6: The determination of surface area.

\begin{tabular}{lccc}
\hline Sieve size $(\mathrm{mm})$ & Percent passing $(\%)$ & Surface area factor $\left(\mathrm{m}^{2} / \mathrm{kg}\right)$ & Surface $\operatorname{area~}\left(\mathrm{m}^{2} / \mathrm{kg}\right)$ \\
\hline 20 & 100 & - & 0.41 \\
14 & 95 & - & - \\
10 & 81 & 0.41 & 0.229 \\
5 & 56 & 0.82 & 0.3854 \\
3.35 & 47 & 1.64 & 0.4264 \\
1.18 & 26 & 4.78 & 0.8604 \\
0.425 & 18 & 12.29 & 1.229 \\
0.15 & 10 & 32.77 & 1.9662 \\
0.075 & 6 & 5.507 \\
\hline \multicolumn{2}{c}{}
\end{tabular}

TABle 7: Metal elements' concentrations on bitumen, crumb rubber powder, and tin slag leachate solution.

\begin{tabular}{lccc}
\hline Metal elements & Bitumen $(\mathrm{ppm})$ & Crumb rubber $(\mathrm{ppm})$ & Tin slag $(\mathrm{ppm})$ \\
\hline Calcium $(\mathrm{Ca})$ & 0.538 & 26.050 & 19.341 \\
Chromium (Cr) & - & 0.007 & 0.003 \\
Iron (Fe) & 0.034 & 2.275 & 5.921 \\
Magnesium (Mg) & 0.116 & 1.020 & 3.369 \\
Manganese (Mn) & - & 0.035 & 0.466 \\
Molybdenum (Mo) & 0.077 & 0.108 & 0.256 \\
Nickel (Ni) & - & 0.035 & 0.034 \\
Antimony (Sb) & 0.074 & 0.045 & 0.051 \\
Selenium (Se) & 0.134 & 0.235 & 0.78 \\
Titanium (Ti) & 0.044 & 0.049 & 0.050 \\
Vanadium (V) & 0.005 & 0.011 & 0.046 \\
Zinc (Zn) & 0.152 & $61.81 \mathrm{ACT} 5$ & 0.495 \\
\hline
\end{tabular}

TABLE 8: Metal elements' concentrations on CRP-modified bitumen leachate solution.

\begin{tabular}{lccc}
\hline Metal elements & Bit. $+5 \%$ CRP $(\mathrm{ppm})$ & Bit. $+10 \%$ CRP $(\mathrm{ppm})$ & Bit. $+15 \%$ CRP $(\mathrm{ppm})$ \\
\hline Calcium $(\mathrm{Ca})$ & 0.271 & 0.542 & 0.798 \\
Iron $(\mathrm{Fe})$ & 0.045 & 0.064 & 0.367 \\
Magnesium $(\mathrm{Mg})$ & 0.226 & 0.314 & 0.956 \\
Molybdenum (Mo) & 0.064 & 0.062 & 0.062 \\
Antimony (Sb) & 0.112 & - & 0.049 \\
Selenium (Se) & - & 0.047 & - \\
Titanium (Ti) & 0.046 & 0.004 & 0.093 \\
Vanadium (V) & 0.004 & 0.060 & 0.006 \\
Zinc (Zn) & 0.084 & & 0.089 \\
\hline
\end{tabular}

Other metals obtained below detectable limits consisted of $\mathrm{Be}, \mathrm{Co}, \mathrm{Cu}, \mathrm{Li}, \mathrm{Mn}, \mathrm{Ni}, \mathrm{Sr}$, and $\mathrm{Tl}$. The analysis was obtained in a minimum of $\mathrm{Ca}, \mathrm{Fe}, \mathrm{Mg}, \mathrm{Mo}, \mathrm{Sb}, \mathrm{Se}, \mathrm{It}, \mathrm{V}$, and $\mathrm{Zn}$. The results showed that not only bitumen mixed sources of toxicity from crumb rubber were emanated but the bitumen itself also contributed to some of these toxic contaminants.
Table 9 shows the metal elements concentrations on bitumen added tin slag mixed leachate solutions. The experimental results show that a bigger portion of tin slag causes higher $\mathrm{Ca}, \mathrm{Fe}, \mathrm{Mg}$, Se, and $\mathrm{Ti}$ contamination in the leachate solutions. Meanwhile, for Mo, Sb, V, and $\mathrm{Zn}$, the fluctuations might be similar to what was mentioned earlier. 
TABLE 9: Metal elements' concentrations on TS-modified bitumen leachate solution.

\begin{tabular}{lccc}
\hline Metal elements & Bit. $+5 \%$ CRP $(\mathrm{ppm})$ & Bit. $+10 \%$ CRP $(\mathrm{ppm})$ & Bit. $+15 \%$ CRP $(\mathrm{ppm})$ \\
\hline Calcium $(\mathrm{Ca})$ & 0.231 & 0.449 & 1.944 \\
Iron (Fe) & 0.045 & 0.064 & 0.367 \\
Magnesium (Mg) & 0.226 & 0.314 & 0.956 \\
Molybdenum (Mo) & 0.064 & 0.062 & 0.062 \\
Antimony (Sb) & 0.112 & - & 0.049 \\
Selenium (Se) & - & 0.127 & 0.168 \\
Titanium (Ti) & 0.046 & 0.047 & 0.093 \\
Vanadium (V) & 0.004 & 0.004 & 0.006 \\
Zinc (Zn) & 0.084 & 0.078 & 0.089 \\
\hline
\end{tabular}

However, metal elements in bitumen added with tin slag mixed leachates solution are very low and below the regulatory level according to the metals hazardous waste parameters stated by US EPA, as shown in Table 4 .

\subsection{Basic and Physical Characterization of the Asphalt Binder}

4.2.1. Softening Point, Penetration, and Elastic Recovery Results. Results tabulated in Table 10 show that the asphalt binder's basic and physical properties are incorporated with crumb rubber powder and tin slag. The properties of all asphalt binders were assessed through penetration tests by evaluating their consistency and softening point. These tests were assisted in identifying the maximum service temperature; meanwhile, an elastic recovery test was used to determine the rate of the elastic response of asphalt binders. Table 10 demonstrates a reduction in penetration, while the softening point value increased with the increasing content of additive. This trend was acceptable on the crumb rubber modified asphalt binder except for the tin slag modified asphalt binder. There were no changes in the penetration and softening point for the tin slag modified asphalt binder, regardless of their concentrations. Nonetheless, the penetration and softening point of tin slag modified asphalt binder exhibited lower than the control asphalt binder. The increase in softening point is essential as the asphalt binder will be less temperature susceptible in resisting permanent deformation. The higher softening point and lower penetration value are due to the stiffening effect of additives. In addition, the different tin slag dosages have resulted in similar results for both the softening point and penetration value due to insufficient elastic response and stiffening effect of tin slag. Bitumen with imbalanced chemical compound and molecular weight distribution has presented a low penetration ratio and penetration index (PI) values resulting in high-temperature susceptibility. The asphalt binder was enhanced by reducing the temperature susceptibility, which led to a higher penetration index. As tabulated in Table 10, crumb rubber powder modified asphalt binders exhibited low susceptibility to temperature compared to the control asphalt binder as the crumb rubber content increased. Nevertheless, the tin slag modified asphalt binders are prone to temperature difference since the penetration index is much lower than the control asphalt binder due to the effects of softening point.
The incorporation of crumb rubber powder has a significant influence on the behavior of modified asphalt binders. The crumb rubber powder-based modified asphalt binder shows a linear increase for all types of rubberized asphalt binder. Elastic recovery findings were comparable to rubberized bitumen ductility outcomes as it demonstrates the high elasticity of modified asphalt binder and its recovery after deformation, enhancing the resistance behavior towards permanent deformation. The outcome of the test presented that a lower percentage of recovery indicated a better recovery. The elastic recovery findings improved for all concentrations of crumb rubber powder from $92.3 \%$ for unmodified asphalt binder to $54 \%, 37 \%$, and $32 \%$ for $5 \%$, $10 \%$, and $15 \%$ for crumb rubber powder modified asphalt binders, respectively. The crumb rubber powder has significantly improved the elastic recovery and indicated that the asphalt binder could recover after removing a certain amount of strain load. This is caused by the natural elastic behavior of the crumb rubber powder, which is also an elastomer. However, the tin slag modified asphalt binders do not portray any elastic recovery since the findings are comparably similar to the control sample. This is because tin slag does not possess an elastic behavior as it is not an elastomer or plastomer. Conclusively, it inferred that the addition of crumb rubber powder significantly affected the basic properties of asphalt binder, while tin slag showed the opposite due to its inelastic behavior.

4.2.2. Torsional Recovery (TR). Results for torsional recovery of asphalt base binder modified with CRP and TS at $5 \%, 10 \%$, and $15 \%$ dosages are presented in Tables 11 and 12 , respectively. The incorporation of CRP and TS as additives in asphalt binder changes the recovery percentage at $5 \%$, $10 \%$, and $15 \%$ compared to the control binder. The torsional recovery percentage of the binder with the incorporation of CRP in Table 11 portrayed a significant improvement in the elasticity of the asphalt binder at all percentages. Moreover, the highest and the least percentage recovery difference observed compared to the conventional asphalt binder were $9 \%$ and $1.7 \%$, respectively. The addition of TS in the asphalt binder, as shown in Table 12, showed a contrary pattern as compared to CRP. The torsional recovery differences of $5 \%$, $10 \%$, and $15 \%$ modified TS binders in the conventional asphalt binder have identical values with $0.5 \%$ due to their similar torsional recovery angle observed. 
TABLE 10: Basic properties of asphalt binders.

\begin{tabular}{lcccccc}
\hline \multirow{2}{*}{ Properties } & \multirow{2}{*}{ Control sample } & \multicolumn{3}{c}{ Crumb rubber content (\%) } & \multicolumn{3}{c}{ Tin slag content (\%) } \\
& & $5 \%$ & $10 \%$ & $15 \%$ & $5 \%$ & $10 \%$ \\
\hline Penetration, dmm & 65 & 58 & 54 & 42 & 56 & 57 \\
Softening point, ${ }^{\circ} \mathrm{C}$ & 50 & 53 & 56 & 61 & 49 & 48 \\
Penetration index & -0.574 & 0.217 & 0.957 & 2.062 & -2.255 & -2.255 \\
Elastic recovery, \% & 92.3 & 54 & 37 & 32 & 91.67 & 91 \\
Ductility, cm & $>100$ & $>100$ & $>100$ & $>100$ & $>100$ & -2.255 \\
\hline
\end{tabular}

TABLE 11: Torsional recovery results of CRP modified binders.

\begin{tabular}{lccc}
\hline Asphalt binder & Recovered angle $\left({ }^{\circ}\right)$ & Torsional recovery (\%) & \% (differences) $T_{R}$ \\
\hline Control & 1 & 0.6 & - \\
$5 \%$ CRP & 4.2 & 2.3 & 1.7 \\
$10 \%$ CRP & 11.1 & 6.1 & 5.5 \\
$15 \%$ CRP & 17.2 & 9.6 & 9.0 \\
\hline
\end{tabular}

TABLE 12: Torsional recovery results of TS modified binders.

\begin{tabular}{lccc}
\hline Asphalt binders & Recovered angle $\left(^{\circ}\right)$ & Torsional recovery (\%) & \% (differences) $T_{R}$ \\
\hline Control & 1 & 0.6 & - \\
$5 \%$ TS & 2.0 & 1.1 & 0.5 \\
$10 \%$ TS & 2.0 & 1.1 & 0.5 \\
$15 \%$ TS & 2.0 & 1.1 & 0.5 \\
\hline
\end{tabular}

Conclusively, it deduced that the incorporation of CRP and TS, which was influencing the formation of crystalline network lattice in the binder structure, resulted in returning the pointer of the apparatus to its initial position due to controlled recovery force.

4.2.3. Coatability Index. The coatability results for the conventional asphalt mixture (HMA) and wastes modified asphalt mixtures of CRP and TS are shown in Table 13. Subsequently, the averaged absorption of the three trials with loose mixes and the bare aggregates was tested, and the coating indexes were computed. The conventional HMA findings are compared with wastes modified asphalt mixtures. The coatability testing for the mixtures was conducted by using three different dosages at 5\%,10\%, and 15\% (CRP and TS), respectively. The results of asphalt added with CRP and TS were different from those of the controlled sample. The coating index of the mixture with CRP showed better performance at $5 \%$ dosage; meanwhile, TS performed better at $10 \%$ dosage. Moreover, the absorption of the aggregate particles was decreased due to the improvement in coating index by the modified asphalts. However, a low marginal difference was observed between different percentages of TS. The mixtures containing 15\% CRP and TS showed the highest absorption rate corresponding to the lowest coating index. This indicates that absorption and coatability rate was dependent on the dosages and chemical compositions of waste materials. Likewise, the CRP exhibits more elastic and bonding characteristics than the TS. The results show reasonable trends in the variable percentages of CRP and TS in asphalt mixture compared to HMA.
TABLE 13: Coatability test results of the control and waste-modified asphalt mixtures.

\begin{tabular}{lcc}
\hline Specimen & $\begin{array}{c}\text { Water absorption of loose } \\
\operatorname{mix}(\%)\end{array}$ & $\begin{array}{c}\text { Coating } \\
\text { index }\end{array}$ \\
\hline Control & 0.22 & 88.2 \\
$5 \%$ CRP & 0.04 & 97.6 \\
$10 \%$ CRP & 0.11 & 94.5 \\
$15 \%$ CRP & 0.13 & 93.1 \\
$5 \%$ TS & 0.09 & 95.3 \\
$10 \%$ TS & 0.08 & 96.0 \\
$15 \%$ TS & 0.14 & 93.0 \\
\hline
\end{tabular}

\section{Conclusion}

This current study demonstrated the effects of differences in percentages of CRP and TS on the leaching potential, basic, and physical properties, as well as the coatability of asphalt binder. The obtained findings concluded that the quantity of CRP and TS waste materials in bitumen impacts the metal concentration present in mixtures with leachate solutions. Moreover, the higher percentage portion of CRP and TS resulted in a higher increment of the metals content. The existence of metals in bitumen mix was a minor concern due to their low quantity and minimum toxicity. Therefore, this study portrayed that CRP and TS metals content presents an insignificant source of hazard towards the environment and groundwater.

Furthermore, the basic properties of CRP and TS modified binders significantly improved the physical properties (softening point, penetration, elastic recovery, and coatability) of the conventional asphalt binder and modified binder. The modified binders with CRP 
demonstrated a better improvement compared to the base asphalt binder and TS.

Torsional recovery results with CRP incorporation showed an obvious improvement inelastic response of the asphalt binder at all percentages compared to the base asphalt binder and TS samples. In addition, the TS showed an identical elastic response across the percentages considered.

\section{Data Availability}

The data used to support the findings of this study are available from the corresponding author upon request.

\section{Disclosure}

Any opinions, findings, and conclusions expressed in this manuscript are those of the authors and do not necessarily reflect the view of USM.

\section{Conflicts of Interest}

The authors declare that they have no conflicts of interest.

\section{Acknowledgments}

The authors would like to acknowledge the financial support provided by Universiti Sains Malaysia (USM) through the Research University Individual-RUI Grant (1001/PAWAM/ 8014140) and the Short-Term Research Grant (304/ PAWAM/6315402) that enabled this paper to be written. The authors would also like to acknowledge the technicians of the Highway Engineering Laboratory at USM for their kind assistance.

\section{References}

[1] S. Kumar and A. L. Thiruvangodan, Waste tyre management in Malaysia, PhD thesis, Universiti Putra Malaysia, Seri Kembangan, Malaysia, 2006.

[2] Paultan.Org, "Vehicle registrations in Malaysia hit 28.2 million units," 2017, https://paultan.org/2017/10/03/vehicleregistrations-in-malaysia-hit-28-2-million-units.

[3] M. S. Senin, S. Shahidan, S. R. Abdullah, N. A. Guntor, and A. S. Leman, "A review on the suitability of rubberized concrete for concrete bridge decks," IOP Conference Series: Materials Science and Engineering, vol. 271, no. 1, 2017.

[4] M. G. Mohamed and H. A. Laz, "Tire hazardous, disposal, and recycling," Journal of Applied and Industrial Sciences, vol. 2, no. 2, pp. 63-74, 2014.

[5] N. E. Khamsan, N. Bidin, S. Islam et al., "Recycling of pneumatic scrap tyre into nano-crumb rubber by pulsed laser ablation in different $\mathrm{pH}$ media," Journal of Physics: Conference Series, vol. 1027, no. 1, 2018.

[6] X. Shu and B. Huang, "Recycling of waste tire rubber in asphalt and portland cement concrete: an overview," Construction and Building Materials, vol. 67, pp. 217-224, 2014.

[7] V. Gopinath, A. M. Vijaya, and D. Prasannan, "An overview of recycling of crumb-rubber in asphalt and concrete structures," International Journal on Applications in Civil and Environmental Engineering, vol. 2, no. 4, pp. 17-22, 2016.

[8] M. Sulyman, M. Sienkiewicz, and J. Haponiuk, "Asphalt pavement material improvement: a review," International
Journal of Environment and Sustainable Development, vol. 5, no. 5, pp. 444-454, 2014.

[9] K. Yan, H. Sun, L. You, and S. Wu, "Characteristics of waste tire rubber (WTR) and amorphous poly alpha olefin (APAO) compound modified porous asphalt mixtures," Construction and Building Materials, vol. 253, Article ID 119071, 2020.

[10] V. S. Punith, S. N. Suresha, S. Raju, S. Bose, and A. Veeraragavan, "Laboratory investigation of open-graded friction-course mixtures containing polymers and cellulose fibers," Journal of Transportation Engineering, vol. 138, no. 1, pp. 67-74, 2011.

[11] K. Yan, Z. Hong, L. You, J. Ou, and M. Miljković, "Influence of ethylene-vinyl acetate on the performance improvements of low-density polyethylene-modified bitumen," Journal of Cleaner Production, vol. 278, 2021.

[12] F. A. Aisien, F. K. Hymore, and R. O. Ebewele, "Application of ground scrap tire rubbers in asphalt concrete pavements," Indian Journal of Engineering and Materials Sciences, vol. 13, no. 4, pp. 333-338, 2006.

[13] D. Lo Presti, "Recycled Tyre Rubber Modified Bitumens for road asphalt mixtures: a literature review," Construction and Building Materials, vol. 49, pp. 863-881, 2013.

[14] Opus International Consultants Ltd, "Removing barriers to the use of crumb rubber in roads," NZ Transport Agency research report 578 Contracted research organization, Opus International Consultants Ltd, Wellington, New Zealand, 2015.

[15] B. George and P. E. Way, Asphalt-Rubber Standard Practice Guide, Rubber Pavement Association, Tempe, AZ, USA, 2011.

[16] S. Liu, W. Cao, J. Fang, and S. Shang, "Variance analysis and performance evaluation of different crumb rubber modified (CRM) asphalt," Construction and Building Materials, vol. 23, no. 7, pp. 2701-2708, 2009.

[17] N. S. Mashaan, A. H. Ali, M. R. Karim, and M. Abdelaziz, "A review on using crumb rubber in reinforcement of asphalt pavement," Science World Journal, vol. 2014, Article ID 214612, 2014.

[18] “The boon and bane of rising tin prices," 2018, https://www. theedgemarkets.com/article/boon-and-bane-rising-tinprices.

[19] A. Rustandi, F. W. Nawawi, Y. Pratesa, and A. Cahyadi, "Evaluation of the suitability of tin slag in cementitious materials: mechanical properties and leaching behavior," IOP Conference Series: Materials Science and Engineering, vol. 299, no. 1, 2018.

[20] A. M. Rodríguez-Alloza, J. Gallego, I. Pérez, A. Bonati, and F. Giuliani, "High and low temperature properties of crumb rubber modified binders containing warm mix asphalt additives," Construction and Building Materials, vol. 53, pp. 460-466, 2014.

[21] W. Huang, P. Lin, N. Tang, J. Hu, and F. Xiao, "Effect of crumb rubber degradation on components distribution and rheological properties of terminal blend rubberized asphalt binder," Construction and Building Materials, vol. 151, pp. 897-906, 2017.

[22] L. Han, M. Zheng, and C. Wang, "Current status and development of terminal blend tyre rubber modified asphalt," Construction and Building Materials, vol. 128, pp. 399-409, 2016.

[23] A. Razmi and M. M. Mirsayar, "Fracture resistance of asphalt concrete modified with crumb rubber at low temperatures," International Journal of Pavement Research and Technology, vol. 11, no. 3, pp. 265-273, 2018. 
[24] H. Yu, Z. Leng, F. Xiao, and Z. Gao, "Rheological and chemical characteristics of rubberized binders with nonfoaming warm mix additives," Construction and Building Materials, vol. 111, pp. 671-678, 2016.

[25] M. A. W. Yusof, Investigating the potential for incorporating tin slag in road pavements, $\mathrm{PhD}$ thesis, University of Nottingham, Nottingham, UK, 2005.

[26] "Method 1311, toxicity characteristic leaching procedure," 2015, https://www.epa.gov/sites/production/files/2015-12/ documents/1311.pdf.

[27] "Hazardous waste characteristics, a user-friendly reference document," 2016, https:/www.epa.gov/sites/production/files/ 2016-01/documents/hw-char.pdf.

[28] ASTM D5, Standard Test Method for Penetration of Bituminous Materials, American Society for Testing Materials, Conshohocken, PA, USA, 1997.

[29] ASTM D36, Standard Test Method for Softening point of Bitumen (Ring-and-ball Apparatus), American Society for Testing Materials, Conshohocken, PA, USA, 1995.

[30] AASHTO T51, Standard Method of Test for Ductility of Asphalt Materials, The American Association of State Highway and Transportation Officials, Washington, DC, USA, 2009.

[31] ASTM D6084, Standard Test Method for Elastic Recovery of Asphalt Materials by Ductilimeter, American Society for Testing Materials, Conshohocken, PA, USA, 1997.

[32] ARRB AG:PT/T122, Torsional Recovery of Polymer Modified Binders, Australia Road Research Board, Sydney, Australia, 2006.

[33] AASHTO T 195, Standard Method of Test for Determining Degree of Particle Coating of Asphalt Mixtures, The American Association of State Highway and Transportation Officials, Washington, DC, USA, 2011.

[34] A. Jamshidi, Rheological properties of asphalt binders, performance and sustainability of warm-mix asphalt incorporating sasobit ${ }^{\circledR}, \mathrm{PhD}$ thesis, University Sains Malaysia, George, Malaysia, 2013.

[35] R. Velasquez, G. Cuciniello, D. Swiertz, R. Bonaquist, and H. Bahia, "Methods to evaluate aggregate coating for asphalt mixtures produced at WMA temperatures," in Proceedings of the CTAA Annual Conference Proceedings-Canadian Technical Asphalt Association, vol. 57, p. 225, Vancouver, Canada, November 2012.

[36] F. Yin, E. Arambula, D. Newcomb, and A. Bhasin, "Workability and coatability of foamed warm-mix asphalt," in Proceedings of the Asphalt Pavements-International Conference on Asphalt Pavements, ISAP 2014, vol. 1, pp. 721-730, Raleigh, NC, USA, June 2014.

[37] ASTM D 2872, Standard Test Method for Effect of Heat and Air on a Moving Film of Asphalt (Rolling Thin-Film Oven Test), American Society for Testing Materials, Conshohocken, PA, USA, 1997.

[38] M. R. M. Hasan, Z. You, H. Yin, M. O. Hamzah, S. Chen, and F. Gong, "Assessments of potential service characteristics of ethanol and ethanol- $\mathrm{NaHCO}_{3}$ foamed WMA mixtures," Journal of Materials in Civil Engineering, vol. 31, no. 6, Article ID 04019079, 2019. 